\title{
O que motiva o paciente a procurar assistência médica por cefaleia?
}

\author{
Pedro Augusto Sampaio Rocha Filho', Liliana Raulino Gonçalves ${ }^{2}$, José de Ribamar Coutinho Junior ${ }^{3}$ \\ ${ }^{1}$ Neurologista, ${ }^{2}$ Psicóloga médica, ${ }^{3}$ Residente Neurologia \\ Hospital Universitário Oswaldo Cruz - Universidade de Pernambuco, Brasil
}

Rocha FilhoPA', Gonçalves LR², Coutinho Junior JR. O que motiva o paciente a procurar assistência médica por cefaleia? Headache Medicine. 2012;3(4):206-7

\section{INTRODUÇÃO}

A cefaleia encontra-se entre as queixas mais comuns da humanidade e é também um motivo frequente de consultas médicas, equivalendo a $10 \%$ de todos os atendimentos realizados no programa de saúde da família ${ }^{(1)}$ e sendo a principal causa de atendimento nos ambulatórios de neurologia. ${ }^{(2)}$

Estima-se que a prevalência de cefaleia em todo o mundo seja de 47\%, de migrânea, 10\%; de cefaleia tipo tensional, 38\% e de cefaleia crônica diária, 3\%.(3) A dor de cabeça, em muitos casos não é percebida pela população como uma condição necessária para procurar assistência médica, devido à sua natureza episódica, ou por aliviar com uso de analgésicos de fácil acesso e baixo custo.

Com isso cresce o número de cefaleias por uso abusivo de medicamentos e cefaleias crônicas e, em consequência, há aumento dos custos diretos e indiretos provocados pelas cefaleias. (')

\section{OBJETIVOS}

Verificar expectativas do paciente quanto ao atendimento e o que influencia nessa expectativa.

\section{MÉTODOS}

Pacientes atendidos pela primeira vez no Ambulatório de Cefaleias do Hospital Universitário Oswaldo Cruz da Universidade de Pernambuco no período de 08/01/ 2007 a 15/05/2012 foram entrevistados utilizando-se questionário padronizado e o Hospital Anxiety and Depression Scale.

A associação das variáveis foi verificada através do teste do $\chi^{2}$.

\section{RESULTADOS}

Entrevistaram-se 532 pacientes, idade média $=42,3$ anos $(D P=16,1), 82,5 \%$ do sexo feminino; $37,4 \%$ tinham escolaridade superior ao primeiro grau. Média de médicos consultados anteriormente por cefaleia $=2,5(\mathrm{DP}=3,5)$; $32 \%$ já haviam procurado mais de dois médicos. Tempo médio com cefaleia $=14$ anos $(\mathrm{DP}=12,5) ; 60 \%$ tinham mais de cinco anos com cefaleia. Frequencia média de cefaleia $=16$ dias por mês (DP $=11,2), 48,1 \%$ tinham cefaleia crônica diária, 23,4\% tinham cefaleia tipo tensional, 71 ,2\% tinham migrânea (Tabela 1).

\begin{tabular}{cc} 
Tabela 1 - Características da cefaleia & \\
\hline Tipo de cefaleia & $(\mathrm{n}=532)$ \\
\hline $\begin{array}{c}\text { Frequência de crises maior que 15 dias por mês } \\
\text { por mais de } 3 \text { meses }\end{array}$ & $48 \%$ \\
Cefaleia tipo tensional & \\
Migrânea & $23 \%$ \\
\end{tabular}

Os motivos alegados para se ter a consulta foram: "Preocupação em ter doença grave" (26,2\%); "Fazer um exame complementar" (22,2\%), "Alívio da dor" (19,5\%); "Ter uma explicação" (18,9\%) e "Ter acompanhamento Médico" (13,2\%) (Figura 1).

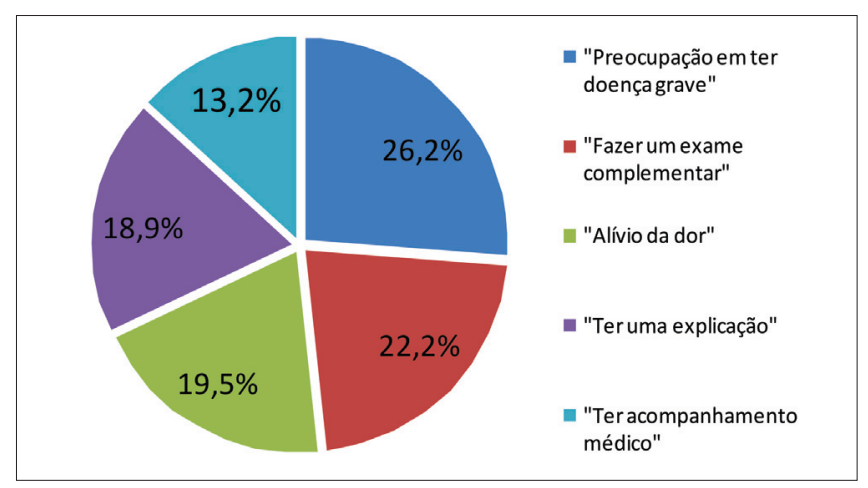

Figura 1 - Motivos alegados para se ter a consulta 
Não houve associação entre o motivo ser "Preocupação em ter doença grave/Fazer um exame complementar" e o gênero, a escolaridade, em ter passado em consulta por mais de dois médicos, em ter diagnóstico de migrânea, de cefaleia tipo tensional, de ansiedade ou depressão, ter cefaleia há mais de dois anos ou ter cefaleia crônica diária.

\section{CONCLUSÕES}

Os motivos mais freqüentemente alegados para se ter a consulta foram: "Preocupação em ter doença grave" (26,2\%); "Fazer um exame complementar"
$(22,2 \%)$. Nenhuma das variáveis estudadas influiu nesses motivos.

\section{REFERÊNCIAS}

1. Oliveira DR, Leite AA, Rocha-Filho PA. Which patients with headache do not seek medical attention? Headache. 2011; $51: 1279-84$

2. Ferri-de-Barros JE, Nitrini R. Which patients does the neurologist assist? Basis for a curriculum in neurology. Arq Neuropsiquiatr. 1996;54:637-44.

3. Stovner LJ, Hagen K, Jensen R, Katsarava Z, Lipton RB, Scher Al, Teiner TJ, Zwart J-A. The global burden of headache: a documentation of headache prevalence and disability worldwide. Cephalalgia. 2007;27:193-210 